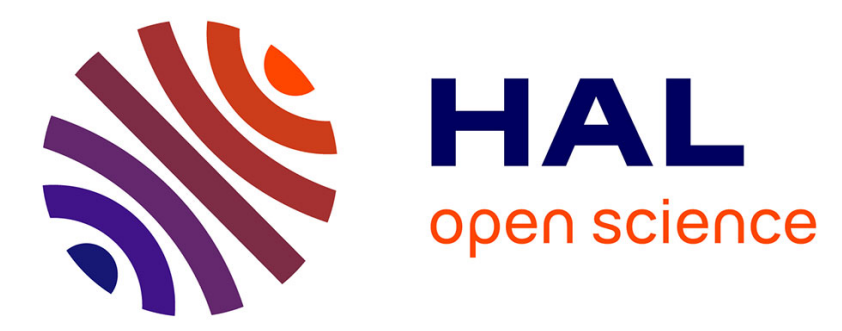

\title{
Pitfalls of high-pass filtering for detecting epileptic oscillations: a technical note on "false" ripples.
}

Christian G. Bénar, Laeticia Chauvière, Fabrice Bartolomei, Fabrice Wendling

\section{To cite this version:}

Christian G. Bénar, Laeticia Chauvière, Fabrice Bartolomei, Fabrice Wendling. Pitfalls of high-pass filtering for detecting epileptic oscillations: a technical note on "false" ripples.. Clinical Neurophysiology, 2010, 121 (3), pp.301-10. 10.1016/j.clinph.2009.10.019 . inserm-00747120

\section{HAL Id: inserm-00747120 https://www.hal.inserm.fr/inserm-00747120}

Submitted on 30 Oct 2012

HAL is a multi-disciplinary open access archive for the deposit and dissemination of scientific research documents, whether they are published or not. The documents may come from teaching and research institutions in France or abroad, or from public or private research centers.
L'archive ouverte pluridisciplinaire HAL, est destinée au dépôt et à la diffusion de documents scientifiques de niveau recherche, publiés ou non, émanant des établissements d'enseignement et de recherche français ou étrangers, des laboratoires publics ou privés. 

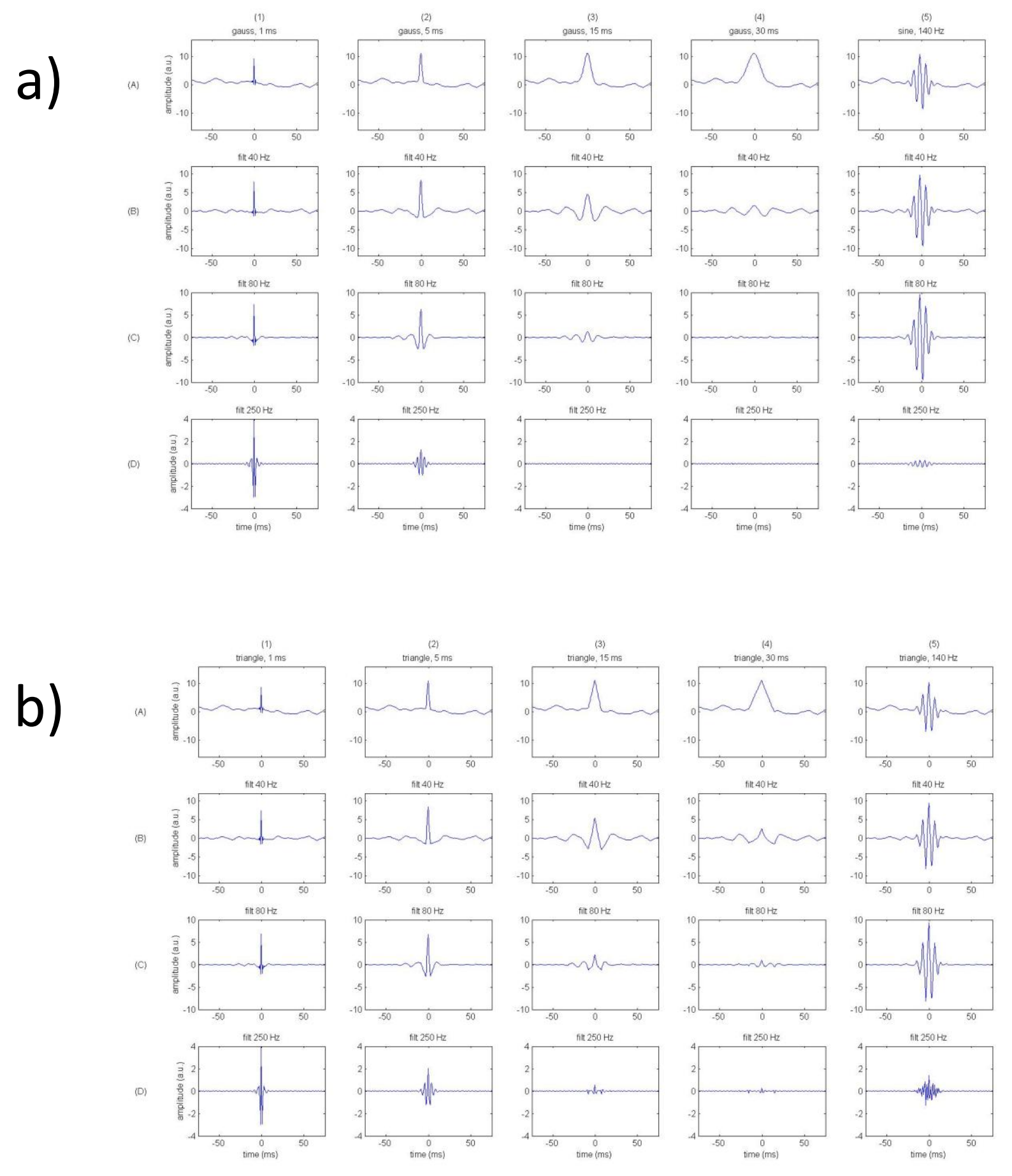

Figure 1 
a)

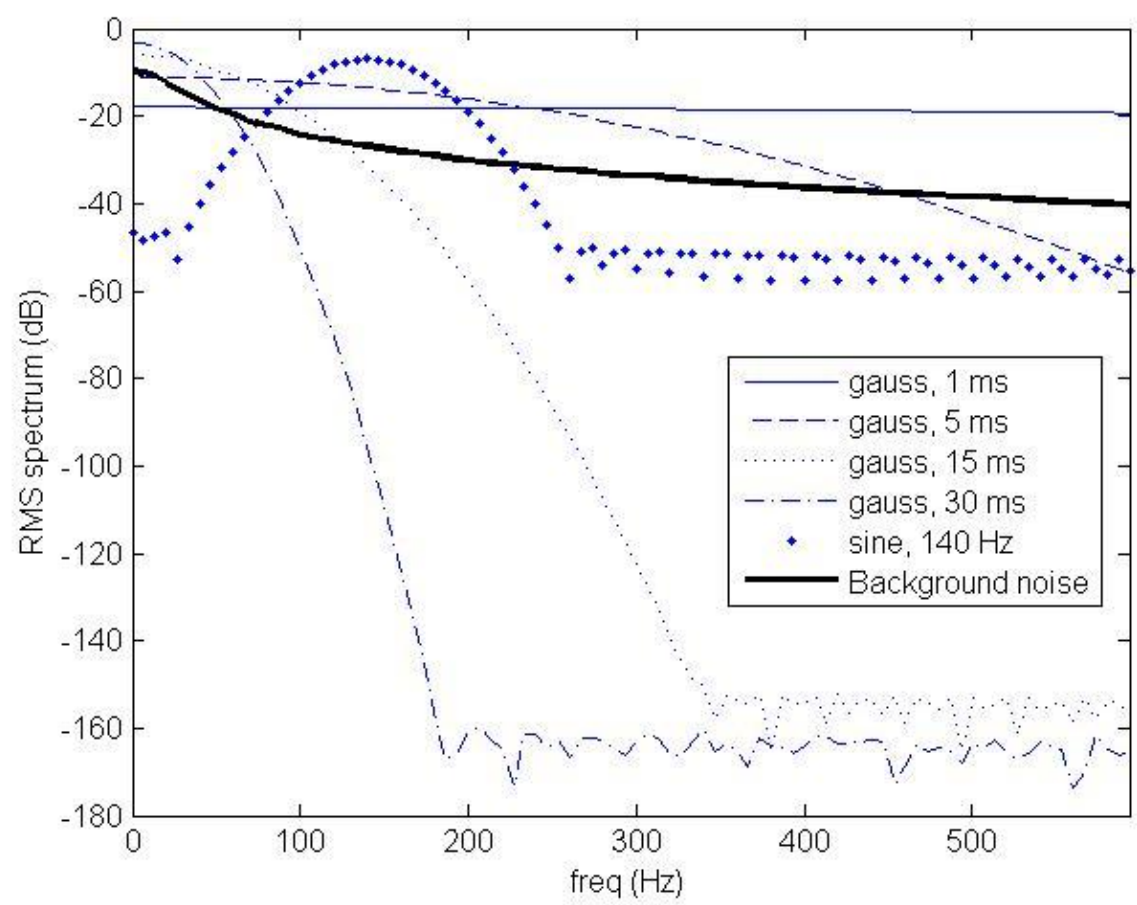

b)

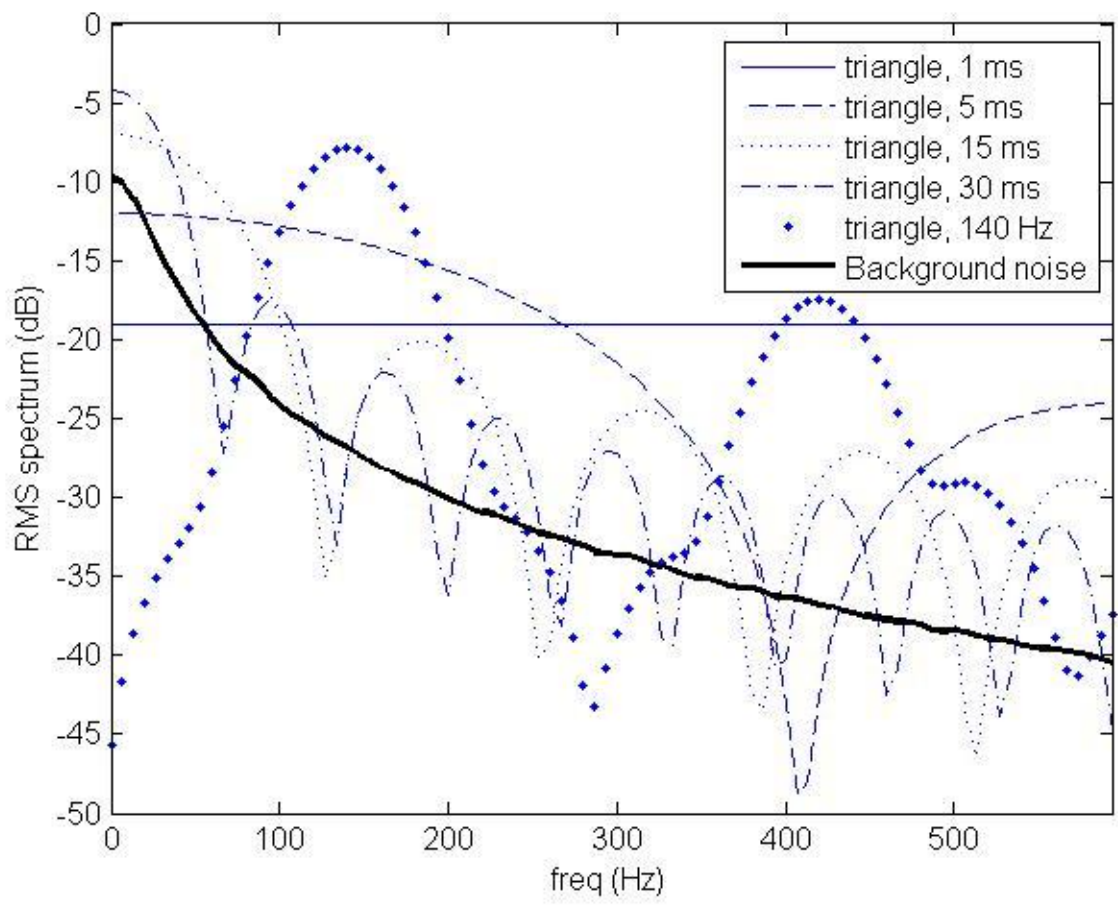


a)
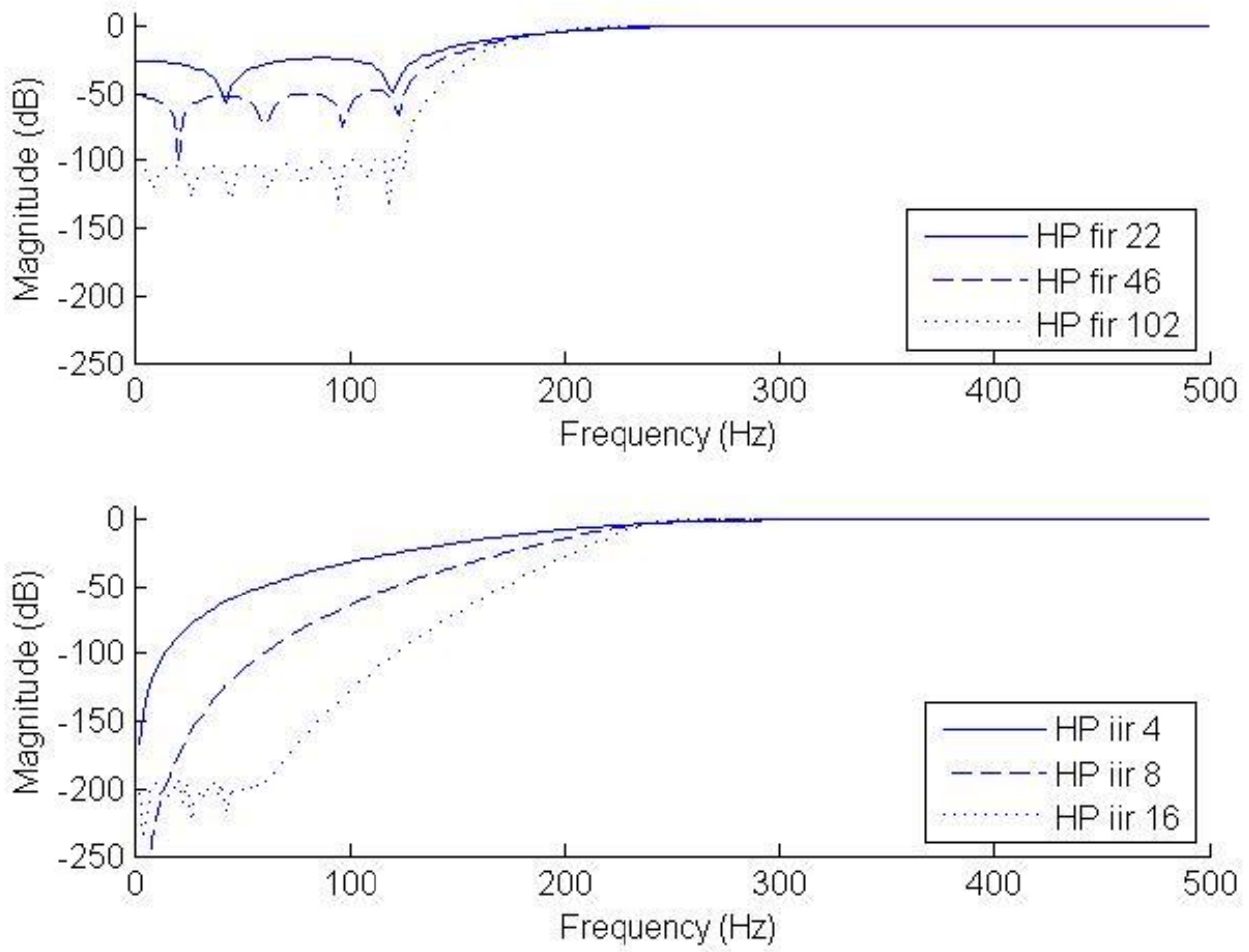

b)
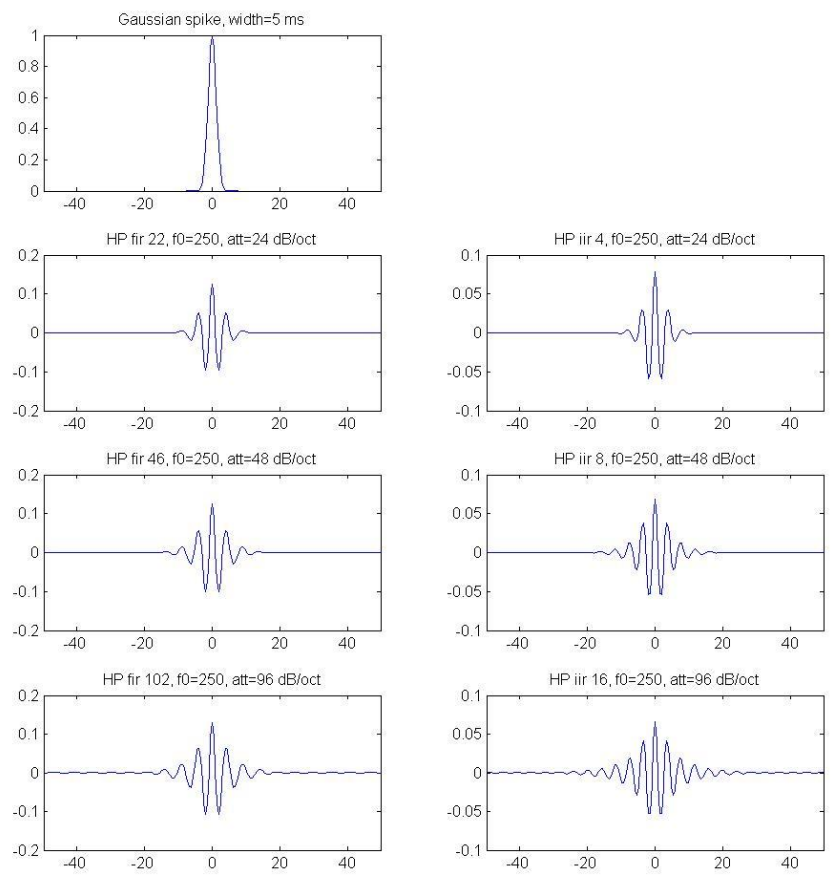

Figure 3 
(A)
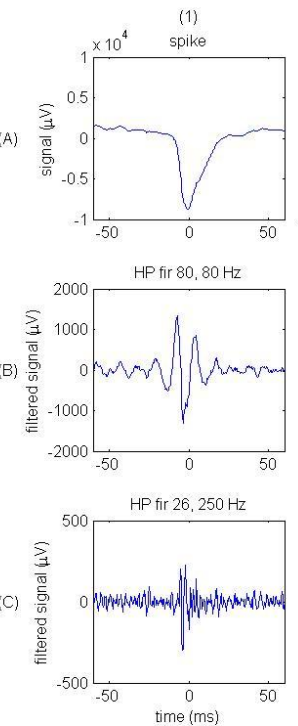

(D)

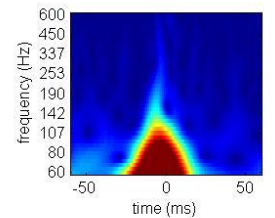

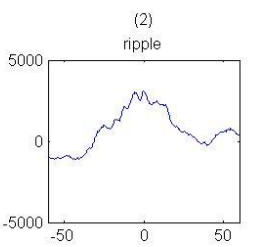
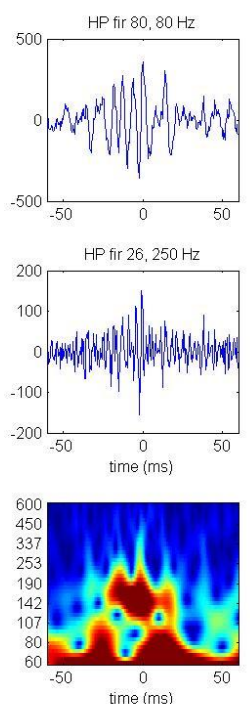
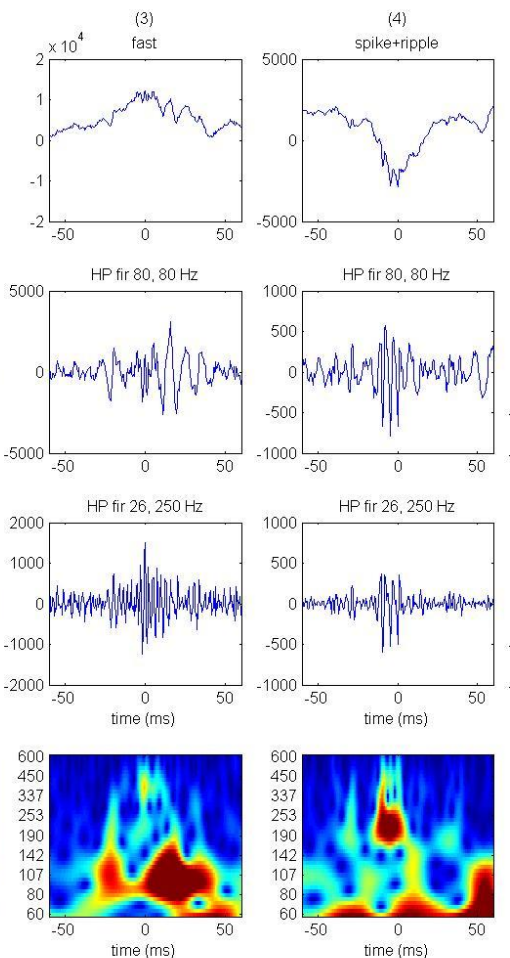
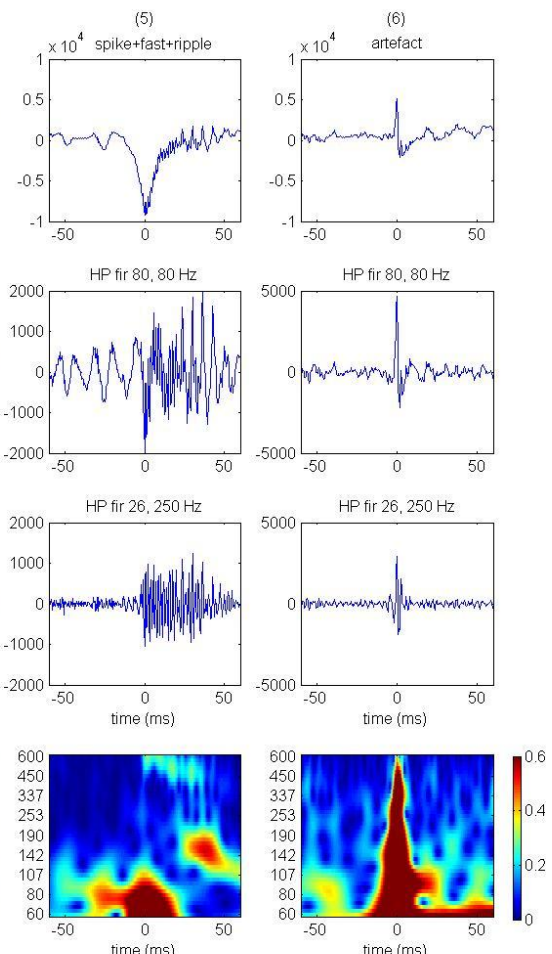
a)
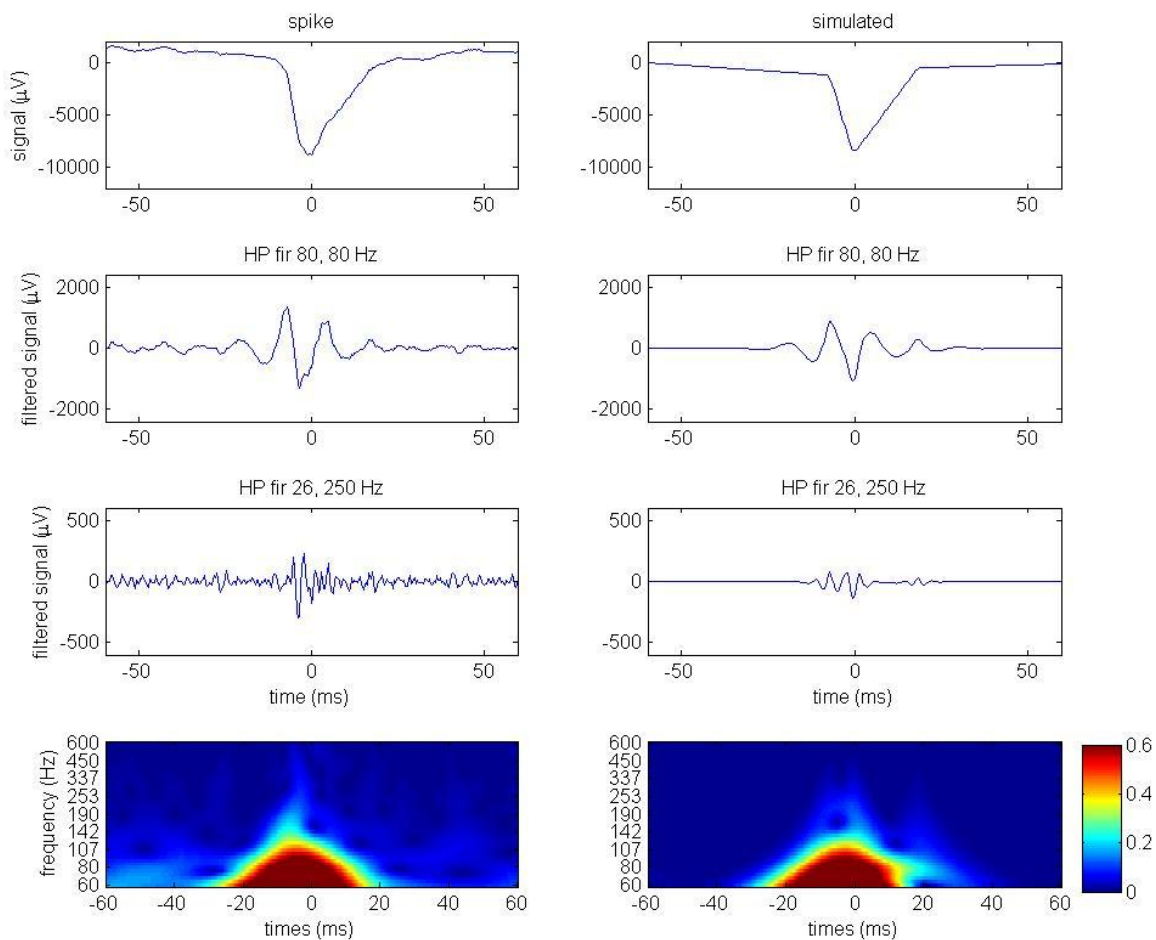

b)
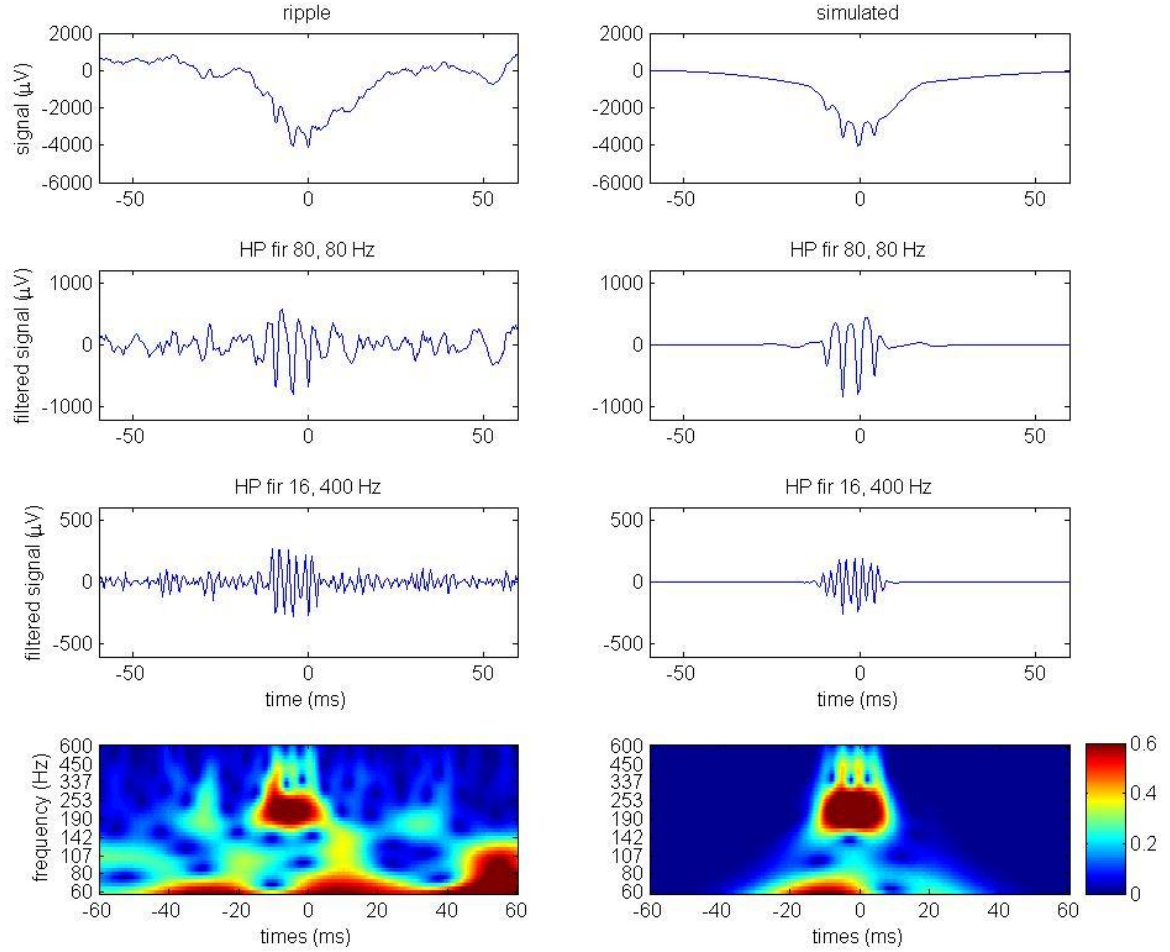

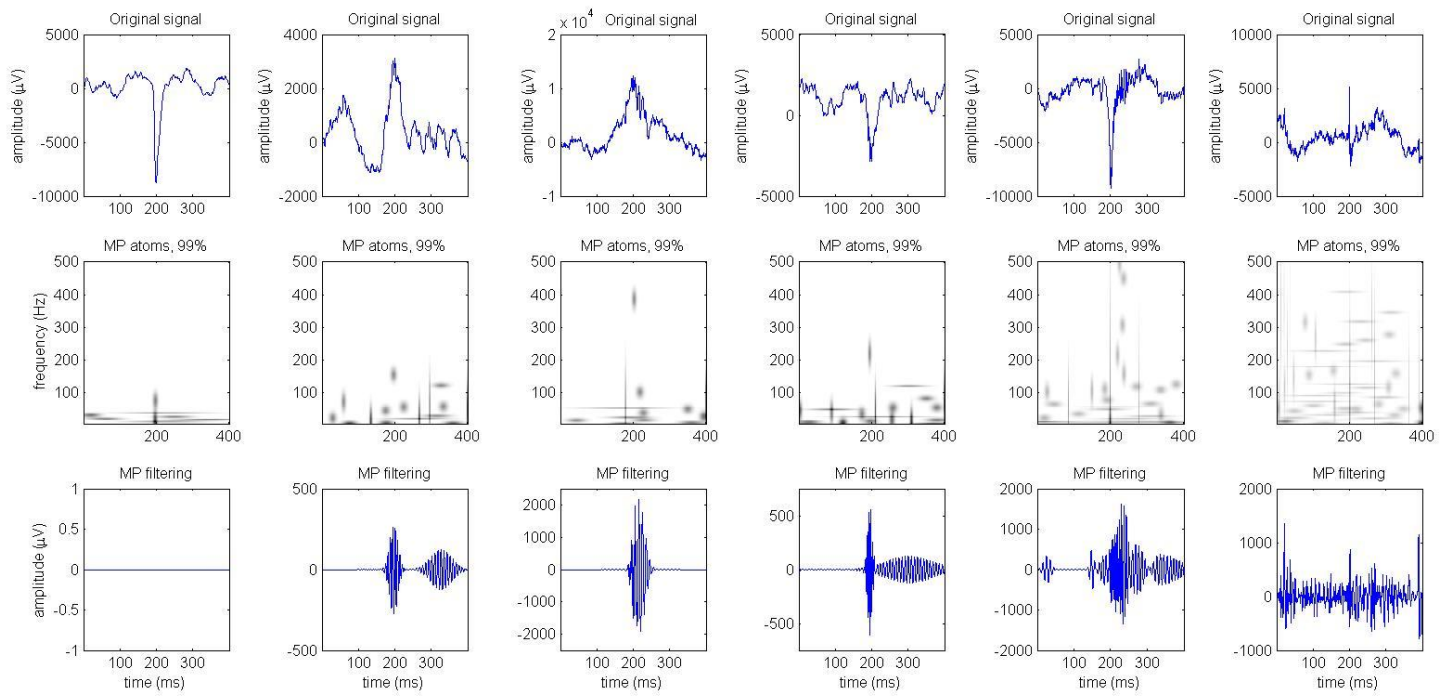

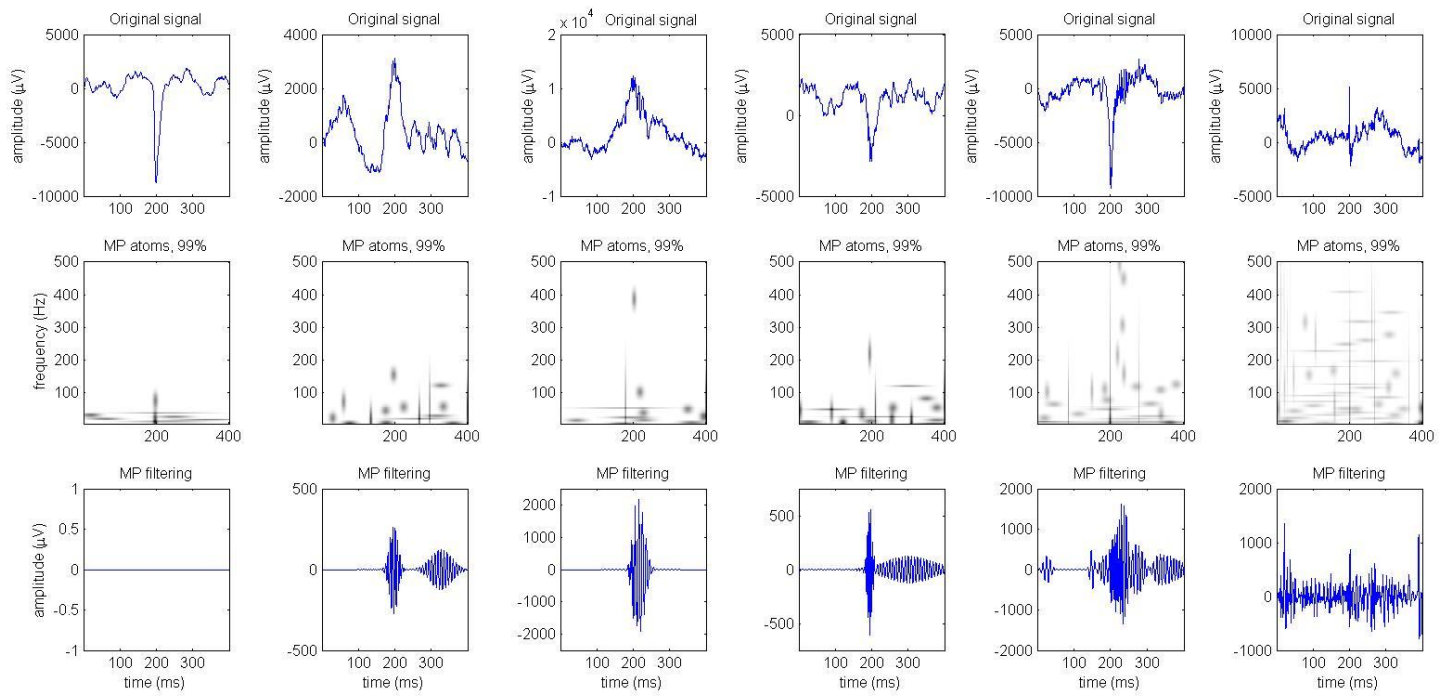

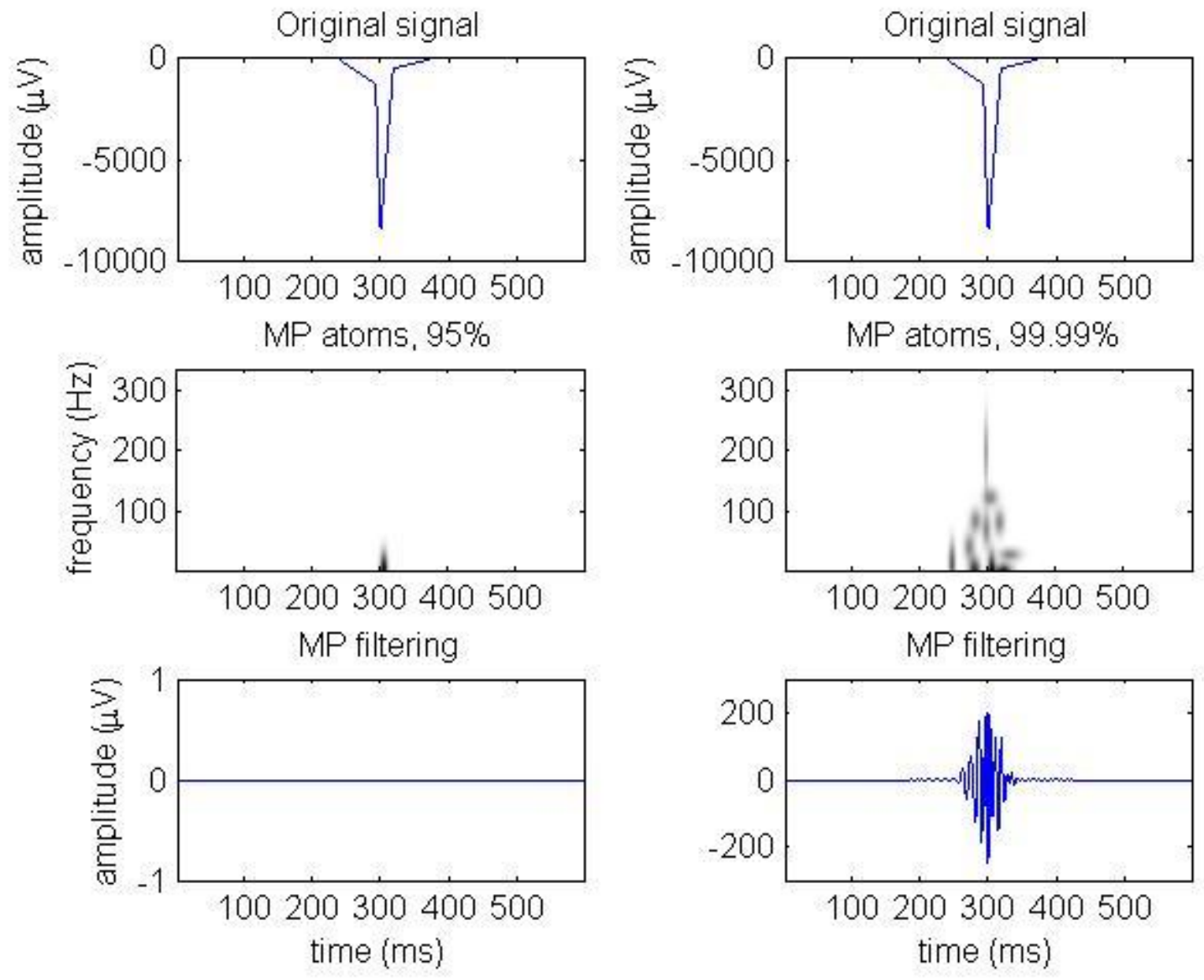